Title:

\title{
Whole-cell recording from Kenyon cells in silkmoths
}

\section{Author affiliation:}

a. Department of Advanced Interdisciplinary Studies, Graduate School of Engineering, The University of Tokyo, 4-6-1 Komaba, Meguro-ku, Tokyo 153-8904, Japan.

b. Research Center for Advanced Science and Technology, The University of Tokyo, 4-6-1 Komaba, Meguro-ku, Tokyo 153-8904, Japan.

c. Graduate School of Life and Environmental Sciences, University of Tsukuba, 1-1-1 Tennodai, Tsukuba Ibaraki 305-8572, Japan.

\section{Names of Authors:}

Masashi Tabuchi ${ }^{\mathbf{a}, \mathbf{b}, \mathbf{1}}$, Shigeki Inoue ${ }^{\mathbf{c}, \mathbf{1}}$, Ryohei Kanzaki ${ }^{\mathbf{a}, \mathbf{b}}$, and Kei Nakatani ${ }^{\mathbf{c}}$

Corresponding author: Kei Nakatani, Ph.D.

Graduate School of Life and Environmental Sciences, University of Tsukuba, 1-1-1

Tennodai, Tsukuba, Ibaraki 305-8572, Japan

Tel: +81-298-53-6672, Fax: +81-298-53-6614, E-mail: nakatani@biol.tsukuba.ac.jp

\section{Author contributions:}

1. These authors contributed equally to this work.

Keywords: insect brain; olfaction; Kenyon cells; patch-clamp recording

\begin{abstract}
:
Kenyon cells (KCs), which are present in the mushroom bodies (MBs) of the insect brain, play an important role in olfactory information processing and associative learning. However, the intrinsic electrophysiological properties of KCs in silkmoth (Bombyx mori) MBs remain unknown. Here, we use whole-cell patch-clamp recordings to elucidate the functional parameters of membrane voltage and voltage-activated ionic currents of KCs in silkmoth MBs. KCs generated action potentials in response to stepping pulses of depolarizing current, and application of
\end{abstract}


GABA-receptor blocker abolished inhibitory synaptic inputs and depolarized resting membrane potential. Pharmacological isolation of $\mathrm{KC}$ voltage-gated ionic currents revealed that KCs express a range of voltage-activated channels, including transient and non-inactivating potassium, sodium, and calcium channels. Our results provide the first electrophysiological characterization of KCs in silkmoth MBs and represent an important step toward understanding neuronal computation that underlies olfactory information processing in silkmoths.

\section{Introduction}

Mushroom bodies (MBs), which are a part of the insect olfactory system, are involved in various functions, such as olfactory associative learning and the integration of multisensory information [7-9]. MBs are anatomically divided into three parts, the calyx, pedunculus, and lobes, and they are made up of tiny intrinsic neurons called Kenyon cells (KCs). KCs respond to odor sparsely, and this sparseness acts as a coincidence detector for synaptic inputs from various neurons, such as projection neurons of the antennal lobe $[2,11,12,16]$.

In the male silkmoth (Bombyx mori), sex pheromones play critical roles in orientation to potential mates, and therefore, the male silkmoth has evolved a highly specialized olfactory system to detect minute amounts of sex pheromones emitted by females [1, 5, 14]. At the level of antennal lobe projection neurons, the neuronal pathway of sex pheromones is spatially segregated from the neuronal pathway of other general odors, including an innervating portion within the calyx of MBs $[6,15]$, suggesting that an integrative decoding of pheromonal information and general odor information could be initiated at the $\mathrm{KC}$ level in MBs. Thus, characterizing the biophysical properties of $\mathrm{KCs}$ is an important step toward better understanding of $\mathrm{MB}$ function in silkmoths. However, little is known about the intrinsic electrophysiological properties of $\mathrm{KCs}$ that underlie the olfactory information processing in the MB circuit. To address this gap, we investigated the properties of KCs using whole-cell patch-clamp recording. Our results revealed intrinsic membrane properties, including pharmacologically isolated voltage-activated potassium, sodium, and calcium ionic currents. This study is an important step toward understanding the function of MBs and is the first to apply whole-cell patch-clamp recording in silkmoths. 


\section{Materials and methods}

\subsection{Silkmoth strain}

The w1-pnd strain (nondiapausing line, colorless eggs and eyes) was used. Larvae were reared on an artificial diet (Silk Mate 2S; Nosan Corporation Bio Department, Japan) at $26^{\circ} \mathrm{C}$ and $60 \%$ relative humidity under a $16: 8 \mathrm{~h}$ (light/dark) cycle. Silkmoths were used within 2-8 days after eclosion.

\subsection{Preparation}

To anesthesize the silkmoths, they were chilled on ice for $30 \mathrm{~min}$ and immobilized on a dissecting chamber following isolation of the head. During the dissection, silkmoth physiological saline solution [140 $\mathrm{mM} \mathrm{NaCl}, 5 \mathrm{mM} \mathrm{KCl}, 7 \mathrm{mM} \mathrm{CaCl} 2,1 \mathrm{mM} \mathrm{MgCl}, 4$ $\mathrm{mM} \quad \mathrm{NaHCO}_{3}, \quad 5 \mathrm{mM}$ Trehalose, $5 \mathrm{mM}$ N-tris (hydroxymethyl) methyl-2-aminoethanesulfonic acid (TES), and $50 \mathrm{mM}$ sucrose; $\mathrm{pH}$ 7.0] was perfused continuously over the preparation. Saline was bubbled with $95 \% \mathrm{O}_{2}$ and $5 \% \mathrm{CO}_{2}$ prior to use. Brains were exposed by opening the head capsules. The large tracheae and the intracranial muscles were removed. To better visualize the recording site and to facilitate efficient penetration of pharmacological chemicals, the MBs were isolated surgically by removing the rest of the brain and the glial sheath that envelops the MBs. For patch-clamp recording, a high-quality seal is essential between the cell body and the recording electrode, and a "clean" plasma membrane surface is a fundamental requirement to create such a seal. For this purpose, the surface of the cell bodies was briefly treated with enzymes collagenase $(0.5 \mathrm{mg} / \mathrm{ml})$ and dispase $(2 \mathrm{mg} / \mathrm{ml})$ at $25^{\circ} \mathrm{C}$ for $5 \mathrm{~min}$ and cleaned with a small stream of saline pressure ejected from a large diameter pipette. In addition, cell surfaces were cleaned by positive pressure from the recording electrode, which was continuously applied using a $1 \mathrm{ml}$ syringe connected to the electrode holder prior to recording. The preparation was immobilized on the bottom of a $35 \times 10 \mathrm{~mm}$ chamber (351008 easy-grip dish; BD, USA) using a plastic anchor and wax. The chamber was placed on the stage of an inverted microscope (Diaphoto 300; Nikon, Japan) and viewed with phase contrast optics and $40 \times$ objective lens. To exchange the bath solution, the preparation was perfused with saline by means of a gravity-driven system.

\subsection{Whole-cell recordings}

Whole-cell recordings were performed at room temperature $\left(25^{\circ} \mathrm{C}\right)$. Patch pipettes (6-10 M $\Omega$ ) were fashioned from borosilicate glass capillaries with a Flaming-Brown 
puller (p-97; Sutter Instrument). The internal solution (150 mM potassium gluconate, $1 \mathrm{mM} \mathrm{MgCl} 2,1 \mathrm{mM}$ EGTA, $5 \mathrm{mM}$ TES, 4 mM Na 2 -ATP, $0.5 \mathrm{mM}$ GTP, $2 \mathrm{mM} \mathrm{NaCl}, 1$ $\mathrm{mM} \mathrm{KCl}$, and $20 \mathrm{mM}$ sucrose; $\mathrm{pH}$ 7.0) was used for whole-cell recording unless otherwise indicated. Biocytin hydrazide $(13 \mathrm{mM})$ was added to the pipette solution in most trials. The purpose of the post hoc staining was to observe the morphological features of the recorded KCs. Detailed procedures for single-cell labeling are described later. Recordings were acquired with an Axopatch 1D amplifier (Molecular Devices) and sampled with Digidata 1200 interface (Molecular Devices). These devices were controlled on a computer using the pCLAMP software (Molecular Devices). Junction potentials were nullified prior to high-resistance (G $\Omega$ ) seal formation. Series resistance was compensated between $60 \%$ and $80 \%$, and linear leakage currents were subtracted from all records. Electrophysiological data were sampled at $10 \mathrm{kHz}$, low-pass filtered at $2 \mathrm{kHz}$, and analyzed with Clampfit (Molecular Devices) and MatLab (MathWorks). All mean values are reported as mean \pm S.E.M. averaged across experiments.

\subsection{Single-cell labeling}

After whole-cell recording, MBs were fixed in 4\% paraformaldehyde in PBS for $24 \mathrm{~h}$ at $4^{\circ} \mathrm{C}$. After washing for $1 \mathrm{~h}$ in several changes of PBST (0.2\% Triton X-100 in PBS), single neurons stained with biocytin were visualized by incubating with Alexa-488-conjugated streptavidin (diluted $1: 100$ ) for $24 \mathrm{~h}$ on a shaker at $4^{\circ} \mathrm{C}$. The MBs were then dehydrated with a concentration gradient of ethanol ranging from $70 \%$ to $100 \%$ and cleared in methyl salicylate. The morphology of the targeted neuron was imaged using a confocal imaging system (LSM-510; Carl Zeiss, Germany) with $488 \mathrm{~nm}$ excitation and a band-pass filter $(505-550 \mathrm{~nm})$. Serial optical sections were acquired at $0.7-1.0 \mu \mathrm{m}$ intervals at a size of $512 \times 512$ pixels, and obtained images were adjusted for contrast and brightness using the LSM Image Browser software (Carl Zeiss).

\subsection{Pharmacological treatment}

Ionic currents were pharmacologically isolated with a combination of blockers, appropriate voltage protocols, and ion substitution. Sodium currents $\left(I_{\mathrm{Na}}\right)$ were blocked with tetrodotoxin (TTX, $\left.10^{-7} \mathrm{M}\right)$. Calcium currents $\left(I_{\mathrm{Ca}}\right)$ were blocked with $\mathrm{CdCl}_{2}\left(10^{-4} \mathrm{M}\right)$. 4-aminopyridine (4-AP, $\left.5 \times 10^{-3} \mathrm{M}\right)$ was used to block A-type $\mathrm{K}^{+}$ currents $\left(I_{\mathrm{A}}\right)$, and tetraethylammonium chloride (TEA, $2 \times 10^{-2} \mathrm{M}$ ) was used to block other sustained $\mathrm{K}^{+}$currents $\left[I_{\mathrm{K}(\mathrm{V})}\right]$. Complete blockage of both of the $\mathrm{K}^{+}$currents was achieved by replacing potassium gluconate in the patch pipette with $\mathrm{CsCl}$. In addition, 
spontaneous inhibitory synaptic inputs were blocked by application of picrotoxin (PTX, $\left.2.5 \times 10^{-4} \mathrm{M}\right)$. To offset the change in osmolarity caused by the presence of additional agents, the sucrose concentration in the silkmoth physiological saline solution described above was modified appropriately.

\section{Results}

\subsection{Membrane voltage properties}

We first recorded the membrane potentials of the KCs in normal physiological saline, and the morphology of the recorded KCs was visualized by post hoc biocytin staining in most trials (Fig. 1A). The morphological type of stained KCs was predominantly " $\alpha$ '/ $\beta$ ' neuron" that was based on the criteria from previous study [4] although we also obtained small percentage of other morphological types. The resting potential was -53 $\pm 2 \mathrm{mV}$ after the establishment of whole-cell configuration $(\mathrm{n}=21)$. The input resistance of the KCs was $1.6 \pm 0.3 \mathrm{G} \Omega(\mathrm{n}=21)$, and whole-cell capacitance was $5.3 \pm$ $0.3 \mathrm{pF}(\mathrm{n}=21)$. Fast inward and slow outward currents were observed in the voltage-clamp recordings (Fig. 1B). Action potentials were elicited in response to stepping pulses of depolarizing current in the current-clamp recordings (Fig. 1C and D). During the recordings, spontaneous inhibitory synaptic inputs were frequently observed, and these inputs were abolished by bath application of $2.5 \times 10^{-4} \mathrm{M}$ PTX (Fig. 1E). We could not observe excitatory synaptic inputs, probably due to disruption of axonal pathway from antennal lobe projection neurons in our preparation. Application of PTX depolarized the resting membrane potential from $-53 \pm 2 \mathrm{mV}(\mathrm{n}=21)$ to $-48 \pm 2.5$ $\mathrm{mV}(\mathrm{n}=11)$ and increased the input resistance from $1.6 \pm 0.3 \mathrm{G} \Omega(\mathrm{n}=21)$ to $5.6 \pm 0.8$ $\mathrm{G} \Omega(\mathrm{n}=11)($ Fig. 1F) .

\subsection{Outward currents}

We next recorded the pharmacologically-isolated ionic currents of KCs. To characterize the voltage-dependent outward currents of KCs in silkmoth MBs, we conducted pharmacological treatments with $10^{-7} \mathrm{M}$ TTX and $10^{-4} \mathrm{M} \mathrm{CdCl}_{2}$. At least two outward currents were apparent. The two currents had different temporal kinetics (transient and sustained dynamics) with pharmacological sensitivity to standard $\mathrm{K}^{+}$ current blockers. The transient outward current $\left(I_{\text {transient }}\right)$ was sensitive to $5 \times 10^{-3} \mathrm{M}$ 4-AP, and the sustained outward current ( $I_{\text {sustained }}$ ) was sensitive to $2 \times 10^{-2} \mathrm{M}$ TEA (Fig. 2A and B). To examine the current-voltage ( $I-V)$ relationship of $I_{\text {transient, voltage }}$ step pulses were added in $10 \mathrm{mV}$ increments between -80 and $60 \mathrm{mV}$, and a hyperpolarizing pre-pulse of $-90 \mathrm{mV}$ was applied to exclude the inactivation of ionic 
currents (Fig. 2C). $I_{\text {transient }}$ was activated by voltage step pulses above $-50 \mathrm{mV}$ and it exhibited rapid inactivation following transient activation during a maintained depolarization.

We also separately examined the TEA-sensitive component as $I_{\text {sustained. The }}$ $I-V$ relationship of the peak $I_{\text {sustained }}$ was determined by application of voltage steps between -80 and $60 \mathrm{mV}$ in $10 \mathrm{mV}$ increments (Fig. 2D). $I_{\text {sustained }}$ was activated by voltage step pulses above $-30 \mathrm{mV}$ and it exhibited no inactivation, and thus, there was no detectable voltage dependence of steady-state inactivation.

\subsection{Inward currents}

To characterize the voltage-dependent inward currents of $\mathrm{KCs}$ in silkmoth $\mathrm{MBs}$, outward currents were blocked by substituting $\mathrm{CsCl}$ for potassium gluconate in the patch pipette solution and by adding 4-AP $\left(5 \times 10^{-3} \mathrm{M}\right)$ and TEA $\left(2 \times 10^{-2} \mathrm{M}\right)$ in the extracellular bath solution. This treatment completely blocked outward currents. After pharmacological treatment, the remaining inward current consisted of a rapidly activating/inactivating component and a slowly inactivating component in the KCs, suggesting that $I_{\mathrm{Na}}$ and $I_{\mathrm{Ca}}$ were attributable to these two temporally distinct inward currents, respectively. To isolate $I_{\mathrm{Na}}$, the bath solution was exchanged with a solution containing $\mathrm{CdCl}_{2}\left(10^{-4} \mathrm{M}\right), 4-\mathrm{AP}\left(5 \times 10^{-3} \mathrm{M}\right)$, and TEA $\left(2 \times 10^{-2} \mathrm{M}\right) . \quad I_{\mathrm{Na}}$ is rapidly activated and inactivated (Fig. 3A). The $I-V$ relationship of the peak $I_{\mathrm{Na}}$ was determined by application of voltage steps between -80 and $60 \mathrm{mV}$ in $10 \mathrm{mV}$ increments (Fig. 3B). The current was activated by voltage step pulses above -50 to $-40 \mathrm{mV}$, and maximum current was observed at approximately $-20 \mathrm{mV}$.

Next, we characterized $I_{\mathrm{Ca}}$ of KCs in silkmoth MBs. To measure $I_{\mathrm{Ca}}$, the brain sample preparation was superfused with saline containing TTX $\left(10^{-7} \mathrm{M}\right), 4$-AP $(5 \times$ $\left.10^{-3} \mathrm{M}\right)$, and TEA $\left(2 \times 10^{-2} \mathrm{M}\right)$. Under these pharmacological conditions, rapid activation and slow inactivation of $I_{\mathrm{Ca}}$ were observed (Fig. 3C). The $I-V$ relationship of the peak $I_{\mathrm{Ca}}$ was determined by application of voltage steps between -80 and $60 \mathrm{mV}$ in $10 \mathrm{mV}$ increments (Fig. 3B). The $I_{\mathrm{Ca}}$ was sensitive to $10^{-4} \mathrm{M} \mathrm{CdCl}_{2}$, and activated at potentials more positive than -60 to $-50 \mathrm{mV}$, and the peak was observed at approximately $0 \mathrm{mV}$.

\section{Discussion}

To date, little is known about the ionic current profile underlying neuronal information processing in the olfactory circuit in the KCs of silkmoth MBs. In this study, we first identified intrinsic electrical properties of KCs in silkmoth MBs. This study is an 
important first step toward understanding the functional properties of $\mathrm{KCs}$ and is the first to apply whole-cell patch-clamp recording in the silkmoth.

The KCs in silkmoth MBs generate action potentials in response to depolarizing current injection and express a range of voltage activated channels, including transient and non-inactivating $\mathrm{K}^{+}, \mathrm{Na}^{+}$, and $\mathrm{Ca}^{2+}$ channels, which are pharmacologically sensitive to 4-AP, TEA, TTX, and $\mathrm{Cd}^{2+}$, respectively. Our results are basically consistent with previous observations in other species including the honeybee [13, 17] and cockroach [3]. Quantitative analysis of ionic conductance revealed further similarities between silkmoth KCs and KCs of different insect species. In particular, voltage-clamp recording of $I_{\mathrm{Ca}}$ exhibited a relatively low activation threshold, and this remarkable property of $I_{\mathrm{Ca}}$ is in agreement with previous $\mathrm{KC}$ recordings in other insects [3], suggesting that the voltage dependence of $I_{\mathrm{Ca}}$ is a common feature of insect KCs regardless of the species. By combining the inhibitory synaptic inputs from giant nonspiking inhibitory interneurons [10], this property of $I_{\mathrm{Ca}}$ in KCs may produce highly nonlinear subthreshold properties of membrane potential that are useful for creating brief integration time windows that are only sensitive to simultaneous excitatory inputs, which underlie sparse coding of olfactory signals in MBs.

Morphological features of $\mathrm{KCs}$ in silkmoth $\mathrm{MBs}$ were comprehensively investigated in a previous study [4]. In that study, KCs were classified into four morphological types based on the destination of axonal projections to the subdivisions in the lobes, and it was also observed that different morphological types of KCs had different dendritic morphologies in the calyx [4]. Although our pooled data did not focus on the $\mathrm{KC}$ morphology, further electrophysiological study on the $\mathrm{KCs}$, focusing on morphological-type specific analysis may be essential to better understand the function of MBs in silkmoths.

\section{Conclusion}

We characterized the electrophysiological properties of KCs in silkmoth MBs using whole-cell patch-clamp recording. Pharmacological isolation of voltage-gated ionic currents revealed that the $\mathrm{KCs}$ express a range of voltage-activated channels, including

transient and non-inactivating $\mathrm{K}^{+}, \mathrm{Na}^{+}$, and $\mathrm{Ca}^{2+}$ channels. The biophysical properties examined here will contribute to a better understanding of the neural machinery of information processing in the silkmoth olfactory circuit.

\section{Acknowledgements}


The authors wish to thank Dr. Shigehiro Namiki (The University of Tokyo) for valuable comments on the manuscripts. This work is supported by Japan Society for the Promotion of Science (JSPS; to MT).

\section{References}

[1] A. Butenandt, R. Beckmann, D. Stamm, E. Hecker, Concerning the sexual attractant of the silkmoth Bombyx mori. Purification and composition., $\mathrm{Z}$ Naturforschg 14b (1959) 283-284.

[2] S. Cassenaer, G. Laurent, Hebbian STDP in mushroom bodies facilitates the synchronous flow of olfactory information in locusts, Nature 448 (2007) 709-713.

[3] H. Demmer, P. Kloppenburg, Intrinsic membrane properties and inhibitory synaptic input of kenyon cells as mechanisms for sparse coding?, J Neurophysiol 102 (2009) 1538-1550.

[4] R. Fukushima, R. Kanzaki, Modular subdivision of mushroom bodies by kenyon cells in the silkmoth, J Comp Neurol 513 (2009) 315-330.

[5] K.E. Kaissling, E. Priesner, Die Riechschwelle des Seidenspinners, Naturwissenschaften 57 (1970) 23-28.

[6] R. Kanzaki, K. Soo, Y. Seki, S. Wada, Projections to higher olfactory centers from subdivisions of the antennal lobe macroglomerular complex of the male silkmoth, Chem Senses 28 (2003) 113-130.

[7] Y. Li, N.J. Strausfeld, Morphology and sensory modality of mushroom body extrinsic neurons in the brain of the cockroach, Periplaneta americana, J Comp Neurol 387 (1997) 631-650.

[8] R. Menzel, Searching for the memory trace in a mini-brain, the honeybee, Learn Mem 8 (2001) 53-62.

[9] M. Mizunami, J.M. Weibrecht, N.J. Strausfeld, Mushroom bodies of the cockroach: their participation in place memory, J Comp Neurol 402 (1998) 520-537.

[10] M. Papadopoulou, S. Cassenaer, T. Nowotny, G. Laurent, Normalization for sparse encoding of odors by a wide-field interneuron, Science 332 (2011) 721-725.

[11] J. Perez-Orive, M. Bazhenov, G. Laurent, Intrinsic and circuit properties favor coincidence detection for decoding oscillatory input, J Neurosci 24 (2004) 6037-6047.

[12] J. Perez-Orive, O. Mazor, G.C. Turner, S. Cassenaer, R.I. Wilson, G. Laurent, 
Oscillations and sparsening of odor representations in the mushroom body, Science 297 (2002) 359-365.

[13] S. Schafer, H. Rosenboom, R. Menzel, Ionic currents of Kenyon cells from the mushroom body of the honeybee, J Neurosci 14 (1994) 4600-4612.

[14] D. Schneider, Insect olfaction: deciphering system for chemical messages, Science 163 (1969) 1031-1037.

[15] Y. Seki, H. Aonuma, R. Kanzaki, Pheromone processing center in the protocerebrum of Bombyx mori revealed by nitric oxide-induced anti-cGMP immunocytochemistry, J Comp Neurol 481 (2005) 340-351.

[16] G.C. Turner, M. Bazhenov, G. Laurent, Olfactory representations by Drosophila mushroom body neurons, J Neurophysiol 99 (2008) 734-746.

[17] D.G. Wustenberg, M. Boytcheva, B. Grunewald, J.H. Byrne, R. Menzel, D.A. Baxter, Current- and voltage-clamp recordings and computer simulations of Kenyon cells in the honeybee, J Neurophysiol 92 (2004) 2589-2603.

\section{Figure legends:}

Fig. 1. Whole-cell recordings of KCs in normal physiological saline.

(A) Morphological image of the recorded $\mathrm{KCs}$ visualized by post hoc biocytin staining. Ca, calyx; d, dorsal; and m, medial. Scale bar $=100 \mu \mathrm{m}$.

(B) Whole-cell voltage-clamp recordings of $\mathrm{KCs}$ showing their typical voltage-dependent currents. Holding potential was stepped in $10 \mathrm{mV}$ increments between -80 and $60 \mathrm{mV}$ following a pre-pulse of $-90 \mathrm{mV}$.

(C) Whole-cell current-clamp recordings of $\mathrm{KCs}$ showing their typical membrane voltage responses to current steps. Current injection was stepped in $20 \mathrm{pA}$ increments between -80 and $100 \mathrm{pA}$.

(D) Mean frequency of action potentials elicited in response to current injections ranging from $0 \mathrm{pA}$ to $100 \mathrm{pA}(\mathrm{n}=12)$.

(E) Spontaneous inhibitory postsynaptic potentials were observed in KCs under normal physiological conditions (saline control) and they were inhibited by bath application of $2.5 \times 10^{-4} \mathrm{M}$ picrotoxin (PTX).

(F) KCs treated with bath application of $2.5 \times 10^{-4}$ M PTX (gray; $\mathrm{n}=11$ ) differed significantly $(\mathrm{P}<0.05$ with Wilcoxon signed rank test) from the saline control KCs (black; $\mathrm{n}=21$ ) in resting membrane potential and input resistance.

Fig. 2. Whole-cell recordings of pharmacologically-isolated outward currents of KCs in the voltage-clamp mode. 
(A) Voltage-dependent activation of $\left(I_{\mathrm{A}}\right)$ in the KCs loaded with potassium gluconate patch pipette internal solution and bathed in a solution containing $10^{-7} \mathrm{M}$ TTX, $10^{-4} \mathrm{M}$ $\mathrm{CdCl}_{2}$, and $2 \times 10^{-2} \mathrm{M}$ TEA. Holding potential was stepped in $10 \mathrm{mV}$ increments between -80 and $60 \mathrm{mV}$ following a pre-pulse of $-90 \mathrm{mV}$.

(B) Voltage-dependent activation of $\left[I_{\mathrm{K}(\mathrm{V})}\right]$ in the $\mathrm{KCs}$ loaded with potassium gluconate patch pipette internal solution and bathed in a solution containing $10^{-7} \mathrm{M}$ TTX, $10^{-4} \mathrm{M}$ $\mathrm{CdCl}_{2}$, and $5 \times 10^{-3} \mathrm{M} 4$-AP. Holding potential was stepped in $10 \mathrm{mV}$ increments between -80 and $60 \mathrm{mV}$ following a pre-pulse of $-90 \mathrm{mV}$.

(C) $I-V$ relationships for $I_{\mathrm{A}}$ peak current amplitudes measured in the $\mathrm{KCs}(\mathrm{n}=5)$.

(D) $I-V$ relationships for $I_{\mathrm{K}(\mathrm{V})}$ plateau current amplitudes measured in the $\mathrm{KCs}(\mathrm{n}=6)$.

Fig. 3. Whole-cell recordings of pharmacologically-isolated inward currents in voltage clamp configuration.

(A) Voltage-dependent activation of $I_{\mathrm{Na}}$ in the $\mathrm{KCs}$ loaded with $\mathrm{CsCl}$ patch pipette internal solution and bathed in a solution containing $10^{-4} \mathrm{M} \mathrm{CdCl}_{2}, 5 \times 10^{-3} \mathrm{M} 4$-AP, and $2 \times 10^{-2} \mathrm{M}$ TEA. Holding potential was stepped in $10 \mathrm{mV}$ increments between -80 and $60 \mathrm{mV}$ following a pre-pulse of $-90 \mathrm{mV}$.

(B) $I-V$ relationships for peak $I_{\mathrm{Na}}$ amplitudes measured in the $\mathrm{KCs}(\mathrm{n}=7)$.

(C) Voltage-dependent activation of $I_{\mathrm{Ca}}$, which was measured during the step depolarization protocol described above in cells loaded with $\mathrm{CsCl}$ patch pipette internal solution and bathed in a solution containing $10^{-7} \mathrm{M} \mathrm{TTX}, 5 \times 10^{-3} \mathrm{M} 4$-AP, and $2 \times 10^{-2}$ $\mathrm{M}$ TEA. Holding potential was stepped in $10 \mathrm{mV}$ increments between -80 and $60 \mathrm{mV}$ following a pre-pulse of $-90 \mathrm{mV}$.

(D) $I-V$ relationships for peak $I_{\mathrm{Ca}}$ amplitudes measured in the $\mathrm{KCs}(\mathrm{n}=6)$. 


\section{Figure}

\section{(A) \\ $\operatorname{TEA}\left(2 \times 10^{-2} \mathrm{M}\right)$}

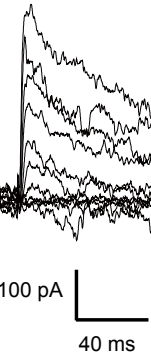

(C)
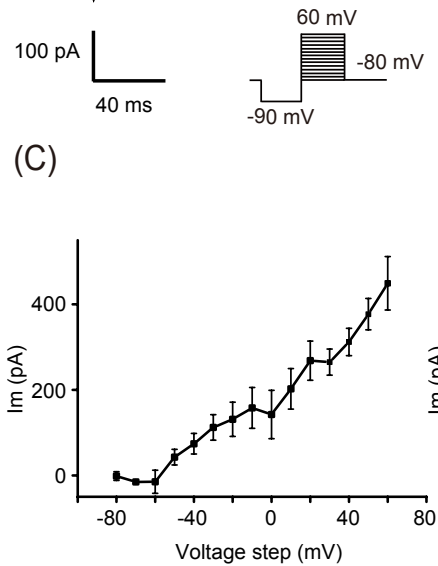

(B) $\quad 4-\mathrm{AP}\left(5 \times 10^{-3} \mathrm{M}\right)$

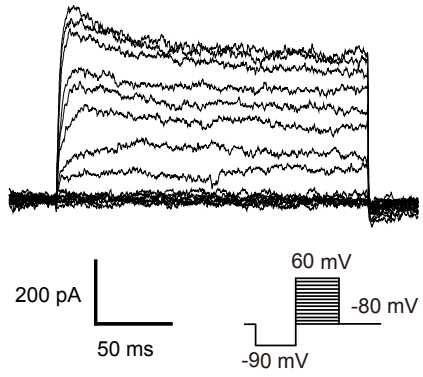

(D)

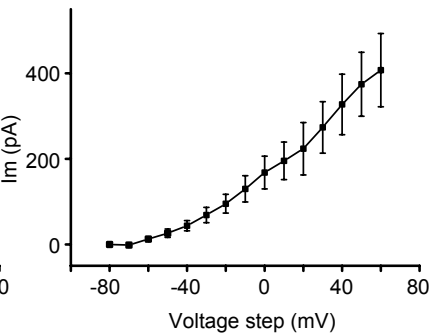




\section{Figure}

(A)

(B)

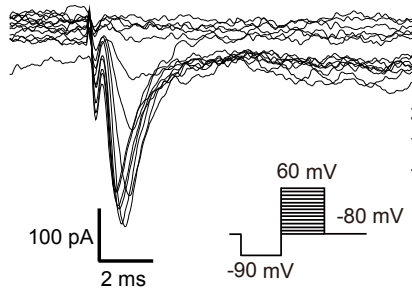

(C)
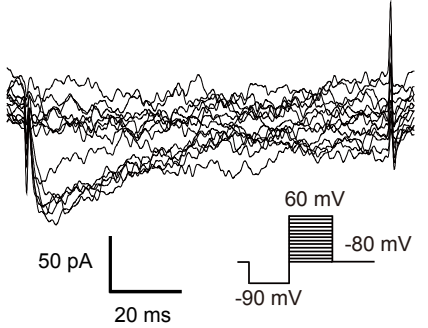

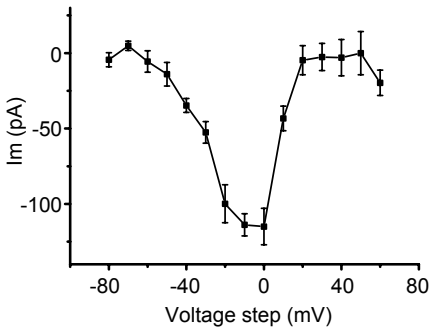

